\title{
Liquid-crystalline gels exhibiting electrooptical light scattering properties: fibrous polymerized network of a lysine-based gelator having acrylate moieties
}

\begin{abstract}
Hiroki Eimura ${ }^{1}$, Masafumi Yoshio ${ }^{1}$, Yoshiko Shoji ${ }^{1}$, Kenji Hanabusa ${ }^{2}$ and Takashi Kato ${ }^{1}$
New liquid-crystalline (LC) gels composed of a lysine-based bisurea derivative having terminal acrylate moieties and a nematic liquid crystal, 4-cyano-4'-pentylbiphenyl, have been prepared to develop light-scattering electrooptical materials. Randomly dispersed networks of the polymerizable fibers are obtained by self-assembly of the lysine derivative through the formation of hydrogen bonds in the isotropic phase of the nematic LC molecule. After the isotropic-nematic transition of the LC molecule occurs at $35^{\circ} \mathrm{C}$ on cooling, light-scattering nematic LC gels are formed because of the formation of microphase-separated structures of fibrous solids and the liquid crystal. The fibrous structures are fixed by photopolymerization, leading to the enhancement of thermal stability. The polymerized LC gels exhibit electrooptical switching between light-scattering and transparent states with lower driving voltages than the non-polymerized LC gels. The threshold voltages of the LC gels based on the polymerizable lysine gelator are also lower than those of the LC gels containing a non-polymerizable lysine gelator.
\end{abstract} Polymer Journal (2012) 44, 594-599; doi:10.1038/pj.2012.21; published online 21 March 2012

Keywords: electrooptical properties; gel; gelator; hydrogen bond; liquid crystal; photopolymerization; self-assembly

\section{INTRODUCTION}

Liquid crystals have been widely used as electrooptical materials because their molecular alignment can be controlled by external electric fields. ${ }^{1}$ Their electrooptical switching properties can be tuned by the incorporation of self-assembled fibers, ${ }^{2-10}$ organic and inorganic particles, ${ }^{11,12}$ and dendrimers ${ }^{13}$ into liquid crystals as well as the encapsulation or phase separation of liquid crystals in polymer matrices. ${ }^{14-16}$ Liquid-crystalline (LC) physical gels are formed by fibrous self-assembly of small amounts of gelators (0.2-5.0 wt\%) in liquid crystals. ${ }^{2-10}$ In these materials, the liquid crystals and the fibrous aggregates of the gelators form microphase-separated structures. The efficient electrooptical switching and the induction of light-scattering electrooptical effects of nematic liquid crystals were achieved by the formation of finely dispersed fibers of gelators in liquid crystals. ${ }^{5-9}$ The electrooptical properties of the LC physical gels were examined for twisted nematic ${ }^{5,6}$ and light-scattering modes. ${ }^{7}$

To enhance thermal stability of the anisotropic gels, a new type of light-scattering LC gel has been developed by self-assembly of an L-valine-based gelator having methacryloyl moieties and a room temperature nematic liquid crystal. ${ }^{10}$ The gelator formed randomly aligned fibrous aggregates through the formation of intermolecular hydrogen bonds in the isotropic phase of LC molecules. Photopolymerization of the gelator forming the self-assembled fibers led to the preparation of cross-linked fibrous networks, resulting in enhancement of thermal and mechanical stability of the LC gels. The formation of microphase-separated structures of fibrous solids and liquid crystals with the domain size corresponding to the wavelength of visible light is essential for induction of efficient scattering of visible light. However, only a limited number of hydrogen-bonded gelators produce efficient light-scattering LC display materials. ${ }^{7,9,10}$

Our intension here is to develop a new polymerizable gelator based on amino acids for the fabrication of light-scattering nematic LC gels. We focused on the lysine scaffold to design hydrogen-bonded gelators. ${ }^{17-20}$ In our previous study, it was found that the lysinebased gelators can be used for light-scattering electrooptical materials exhibiting high contrast, low driving voltage and fast response times. ${ }^{6}$ Therefore, the introduction of polymerizable groups into the lysinebased gelators is expected to produce efficient and stable lightscattering nematic LC gels.

Herein, we report on the synthesis of a new L-lysine-based gelator containing acrylate moieties (1) and the fibrous self-assembly of the gelator in nematic liquid crystal 2 (Figure 1 and Scheme 1). The electrooptical properties of the nematic LC gels before and after photopolymerization are compared with an L-lysine-based gelator 3, containing no polymerizable groups.

${ }^{1}$ Department of Chemistry and Biotechnology, School of Engineering, The University of Tokyo, Tokyo, Japan and ${ }^{2}$ Graduate School of Science and Technology, Shinshu University, Ueda, Nagano, Japan

Correspondence: Professor T Kato, Department of Chemistry and Biotechnology, The University of Tokyo, School of Engineering, Hongo, Bunkyo-ku, Tokyo 113-8656, Japan. E-mail: kato@chiral.t.u-tokyo.ac.jp

Received 8 January 2012; revised 11 February 2012; accepted 13 February 2012; published online 21 March 2012 


\section{EXPERIMENTAL PROCEDURE}

\section{Synthesis of 5}

A mixture of 11-bromoundecanol $(4.94 \mathrm{~g}, 19.7 \mathrm{mmol})$ and lithium acrylate $(2.51 \mathrm{~g}, 24.0 \mathrm{mmol})$ in hexamethylphosphoric triamide $(70 \mathrm{ml})$ was stirred under an Ar atmosphere overnight at room temperature. The reaction mixture was dissolved in ethyl acetate, washed with water and saturated $\mathrm{NaCl}$ aqueous solution. The organic phase was separated and dried over $\mathrm{MgSO}_{4}$, and the solvents were evaporated. The residue was purified by a silica gel column chromatography by gradient elution with hexane-ethyl acetate mixtures (from hexane:ethyl acetate $=4: 1$ to hexane:ethyl acetate $=1: 1)$ to give $5(4.66 \mathrm{~g}$, $19.2 \mathrm{mmol}, 97 \%)$ as a white solid. ${ }^{1} \mathrm{H}$ nuclear magnetic resonance $(400 \mathrm{MHz}$, $\left.\mathrm{CDCl}_{3}\right): \delta=6.43-6.38(\mathrm{~d}, J=17 \mathrm{~Hz}, 1 \mathrm{H}), 6.17-6.11(\mathrm{dd}, J=17,10 \mathrm{~Hz}, 1 \mathrm{H})$, $6.10-5.80(\mathrm{~d}, J=10 \mathrm{~Hz}, 1 \mathrm{H}), 4.17-4.11(\mathrm{t}, J=6.8 \mathrm{~Hz}, 2 \mathrm{H}), 3.67-3.62(\mathrm{t}, J=13$ $\mathrm{Hz}, 2 \mathrm{H}), 1.67-1.56(\mathrm{~m}, 4 \mathrm{H})$ and $1.26(\mathrm{~m}, 14 \mathrm{H})$.

\section{Synthesis of 6}

To the solution of pyridinium dichromate $(10.0 \mathrm{~g}, 6.60 \mathrm{mmol})$ and sodium acetate $(0.492 \mathrm{~g}, 5.80 \mathrm{mmol})$ in $\mathrm{N}, \mathrm{N}$-dimethylformamide $(35 \mathrm{ml})$, the solution of $5(2.20 \mathrm{~g}, 9.08 \mathrm{mmol})$ in $\mathrm{N}, \mathrm{N}$-dimethylformamide $(15 \mathrm{ml})$ was added at $0{ }^{\circ} \mathrm{C}$ and stirred at room temperature overnight. After adding diethyl ether to the reaction mixture, the resulting oily black residue was removed by decantation. The solution was washed with saturated $\mathrm{NH}_{4} \mathrm{Cl}$ aqueous solution, water and saturated $\mathrm{NaCl}$ aqueous solution. The combined organic phase was dried over $\mathrm{MgSO}_{4}$ and evaporated. The residue was purified by a silica gel column chromatography by gradient elution with hexane-ethyl acetate mixtures (from hexane:ethyl acetate $=4: 1$ to hexane:ethyl acetate $=1: 1)$ to yield $6(1.25 \mathrm{~g}$, $4.88 \mathrm{mmol}, 53 \%)$. ${ }^{1} \mathrm{H}$ nuclear magnetic resonance $\left(400 \mathrm{MHz}, \mathrm{CDCl}_{3}\right)$ : $\delta=6.43-6.37 \quad(\mathrm{~d}, \quad J=17 \mathrm{~Hz}, 1 \mathrm{H}), \quad 6.17-6.11 \quad(\mathrm{dd}, J=17,10 \mathrm{~Hz}, 1 \mathrm{H})$, $6.10-5.80(\mathrm{~d}, J=10 \mathrm{~Hz}, 1 \mathrm{H}), 4.17-4.11(\mathrm{t}, J=6.8 \mathrm{~Hz}, 2 \mathrm{H}), 2.37-2.33(\mathrm{t}$, $J=7.2 \mathrm{~Hz}, 2 \mathrm{H})$ and $1.68-1.23(\mathrm{~m}, 16 \mathrm{H})$.

\section{Synthesis of 7}

To the solution of $6(0.89 \mathrm{~g}, 3.47 \mathrm{mmol})$ in toluene $(10 \mathrm{ml})$ and triethylamine $(2 \mathrm{ml})$ was added diphenylphosphoryl azide $(0.8 \mathrm{ml})^{21}$ under an $\mathrm{Ar}$

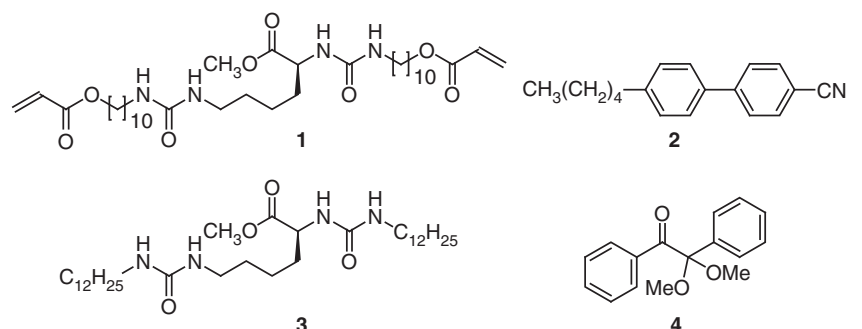

Figure 1 Molecular structures of polymerizable lysine-based gelator 1 , nematic liquid crystal 2, lysine-based gelator $\mathbf{3}$ and photoinitiator $\mathbf{4}$. atmosphere. The solution was stirred at room temperature for $1 \mathrm{~h}$ and further stirred at $60^{\circ} \mathrm{C}$ for $1 \mathrm{~h}$. After the reaction mixtures were cooled to room temperature, the oily precipitate was removed by decantation. The supernatant solution was evaporated. The residue was purified by a short silica gel column chromatography (hexane:ethyl acetate $=4: 1$ ) to yield a crude sample of $7(1.21 \mathrm{~g})$ as a viscous liquid. This sample was immediately used for the next reaction.

\section{Synthesis of 1}

The solution of crude sample $7(1.21 \mathrm{~g})$, L-lysine methyl ester dichloride $(0.338 \mathrm{~g}, 1.45 \mathrm{~g})$ and triethylamine $(1.1 \mathrm{ml})$ in dichloromethane $(20 \mathrm{ml})$ was refluxed under an $\mathrm{Ar}$ atmosphere for $6 \mathrm{~h}$ and stirred overnight at room temperature. The reaction mixture was washed with $5 \% \mathrm{HCl}$ aqueous solution, saturated $\mathrm{NaHCO}_{3}$ aqueous solution, water and brine. The organic phase was dried over $\mathrm{MgSO}_{4}$, and solvents were evaporated. The residue was purified by a silica gel column chromatography (chloroform:methanol $=19: 1$ ) to yield 1 $(0.590 \mathrm{~g}, 0.885 \mathrm{mmol}, 61 \%)$. Infrared (KBr): $v=3344,2925,2851,1727,1629$, 1573, 1466, 1409, 1297, 1274, 1198, 1060, 985 and $811 \mathrm{~cm}^{-1} .{ }^{1} \mathrm{H}$ nuclear magnetic resonance $\left(400 \mathrm{MHz}, \mathrm{CDCl}_{3}\right): \delta=6.42-6.38(\mathrm{~d}, J=17 \mathrm{~Hz}, 2 \mathrm{H})$, 6.16-6.09 (dd, $J=17,10 \mathrm{~Hz}, 2 \mathrm{H}), 5.84-5.81(\mathrm{~d}, J=10 \mathrm{~Hz}, 2 \mathrm{H}), 5.38-5.36$ (d, $J=7.6 \mathrm{~Hz}, 1 \mathrm{H}), 4.80(\mathrm{~m}, 1 \mathrm{H}), 4.69(\mathrm{~m}, 1 \mathrm{H}), 4.43(\mathrm{~m}, 1 \mathrm{H}), 4.42(\mathrm{~m}, 1 \mathrm{H})$, $4.17-4.13(\mathrm{t}, J=6.8 \mathrm{~Hz}, 4 \mathrm{H}), 3.7(\mathrm{~s}, 3 \mathrm{H}), 3.18-3.12(\mathrm{~m}, 6 \mathrm{H})$ and $1.80-1.28(\mathrm{~m}$, $38 \mathrm{H}) .{ }^{13} \mathrm{C}$ nuclear magnetic resonance $\left(100 \mathrm{MHz}, \mathrm{CDCl}_{3}\right): \delta=174.3,166.4$, $158.9,158.2,130.6,128.6,64.7,52.7,52.2,40.5,40.4,39.5,32.0,30.3,29.5$, 29.4, 29.3, 29.2, 28.6, 26.9 and 25.9. Matrix assisted laser desorption/ ionization-mass spectrometry (MALDI-MS): $\mathrm{m} / \mathrm{z} 705.48$ (calcd. $[\mathrm{M}+\mathrm{K}]^{+}$ =705.99). Anal. calcd. for $\mathrm{C}_{35} \mathrm{H}_{62} \mathrm{~N}_{4} \mathrm{O}_{8}$ : C, 63.04; $\mathrm{H}, 9.37$ and $\mathrm{N}, 8.40 \%$. Found: C, 63.00; H, 9.35 and N, 8.75\%.

\section{Preparation of LC gels}

The LC physical gels were prepared by mixing liquid crystal 2 and chloroform solution of gelator $\mathbf{1}$ or $\mathbf{3}$, followed by slow evaporation of the solvent at room temperature. For the LC physical gels of $\mathbf{1}$, photoinitiator $4(0.1 \mathrm{wt} \%)$ was further added. The mixtures were heated to the isotropic liquid states, followed by cooling to the required temperatures. The gelation test was performed by macroscopic observation of the flow of the liquid crystal/gelator mixtures with the test tubes upside down at room temperature.

\section{Measurements of electrooptical properties}

The electrooptical properties of the LC gels in the light-scattering mode were measured in indium tin oxide glass sandwich cells $(3 \mathrm{~cm} \times 3 \mathrm{~cm} \times 16 \mu \mathrm{m})$. The mixtures in the isotropic liquid states were introduced into the cells, followed by cooling to room temperature. The thickness of the sample was fixed to be $16 \mu \mathrm{m}$ by using silica particles. A He-Ne laser $(632.8 \mathrm{~nm})$ was used as the incident light source. AC electric fields $(1 \mathrm{kHz})$ were applied to the cells. The transmitted light intensity was measured with a photodiode. The light intensity for the empty indium tin oxide cell was assumed to be full-scale intensity. The threshold $\left(V_{\text {th }}\right)$ and saturation $\left(V_{\text {sat }}\right)$ voltages were evaluated as voltages required to reach $10 \%$ and $90 \%$ of the maximum change in

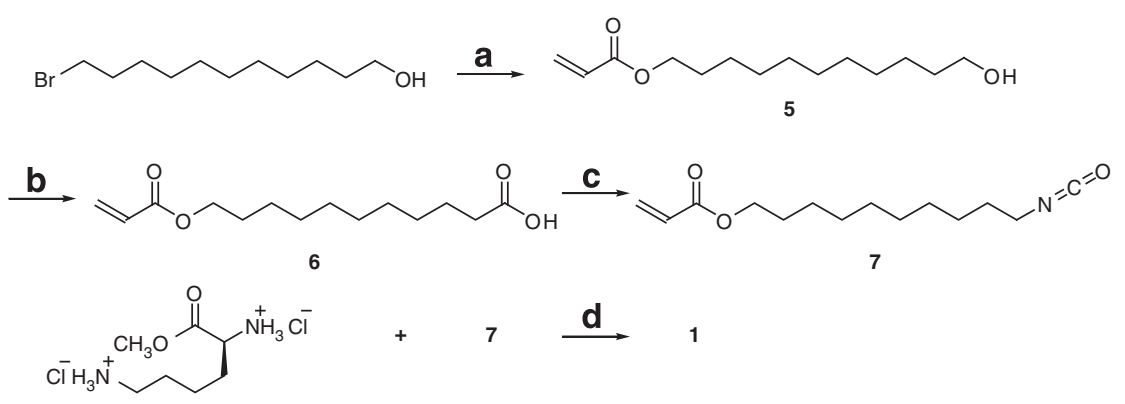

Scheme 1 Synthetic scheme of a lysine-based gelator 1. Conditions: (a) lithium acrylate, hexamethylphosphoric triamide, r.t., 24h (b) pyridinium dichromate, sodium acetate, $\mathrm{N}, \mathrm{N}$-dimethylformamide, $0^{\circ} \mathrm{C}$ to r.t., (c) diphenylphosphoryl azide, triethylamine, toluene, r.t. for $1 \mathrm{~h}, 60^{\circ} \mathrm{C}$ for $1 \mathrm{~h}$ (d) triethylamine, dichloromethane, reflux for $6 \mathrm{~h}$, r.t. for $24 \mathrm{~h}$. 
transmittance, respectively. The rise $\left(\tau_{\text {on }}\right)$ and decay times $\left(\tau_{\text {off }}\right)$ were evaluated as the time periods required to reach $90 \%$ and drop $10 \%$ of the maximum transmittance change upon the application and removal of electric fields, respectively. The transmittances in the on $\left(T_{\text {on }}\right)$ and off $\left(T_{\text {off }}\right)$ states were defined as the transmittances in the presence and absence of an electric field $(80 \mathrm{~V})$, respectively.

\section{RESULTS AND DISCUSSION}

Design and synthesis of polymerizable lysine-based gelator

A variety of L-lysine-based gelators such as the bisamide, bisurea and amide-urea derivatives having long alkyl chains were prepared by Hanabusa and coworkers. ${ }^{17-18}$ The L-lysine derivatives have been reported to be efficient gelators. We previously reported that an L-lysine derivative with amide and urea moieties gelated room temperature nematic liquid crystals at the low concentration of the gelator because of the formation of the hydrogen-bonded selfassembled fibers. ${ }^{6,8,9}$ The resulting nematic LC gels exhibited excellent light-scattering electrooptical switching. ${ }^{9}$ The formation of microphase-separated nanofibrous network of gelators in liquid crystals is important for the enhancement of the electrooptical properties. $^{7}$ The gelators containing an L-lysine-based scaffold were chosen to yield the high-performance light-scattering LC gels. We designed a polymerizable L-lysine-based gelator 1 (Figure 1) in order to obtain thermally stable LC gels through covalently cross-linking after the formation of the fibrous networks. Two acrylate groups are introduced into the extremity of the alkyl chains of L-lysine-based bisurea gelator $3^{19-20}$ (Figure 1). Photopolymerization of selfassembled fibers is an effective method to produce stable gels. ${ }^{22-29}$ The enhancement of the thermal stability and durability of the self-assembled LC gels is essential for practical applications.

Compound 1 was synthesized according to Scheme 1. Isocyanate 7 containing an acrylate moiety was synthesized by the Crutius rearrangement of the acyl azide prepared by the reaction of the carboxylic acid 6 and diphenylphosphoryl azide. ${ }^{21}$ Isocyanate 7 was reacted with L-lysine methyl ester dihydrochloride in the presence of triethylamine to yield bisurea derivative $\mathbf{1}$.

\section{Formation of LC physical gels}

Compounds 1 and $\mathbf{3}$ gelated room temperature nematic liquid crystal 2. The LC gels containing $0.5,1.0$ and $2.0 \mathrm{wt} \%$ of 1 or 3 were white soft solids at room temperature owing to the light scattering. The morphologies of $\mathbf{1}$ and $\mathbf{3}$ were examined by scanning electron microscope observation. Figure 2 shows the scanning electron microscope. image of the xerogel obtained from the LC gel containing $1.0 \mathrm{wt} \%$ of gelators. The entangled fibrous networks are seen for 1 and 3 , and the approximate diameter of the fibrous aggregates is $0.9 \mu \mathrm{m}$ for 1 and $1.2 \mu \mathrm{m}$ for 3 . Optical microscope observation for the mixture of $1(1.0 \mathrm{wt} \%)$ and $\mathbf{2}$ confirmed that the fibrous network of 1 was formed in the isotropic liquid of 2 at $40^{\circ} \mathrm{C}$ (Supplementary Figure S1). The differential scanning calorimetry thermogram of the mixture of $\mathbf{1}(2.0 \mathrm{wt} \%$ ) and 2 on cooling (Figure 3 ) showed a broad exothermic peak between $49^{\circ} \mathrm{C}$ and $37^{\circ} \mathrm{C}$ and an exothermic peak between $36^{\circ} \mathrm{C}$ and $27^{\circ} \mathrm{C}$. These peaks can be attributed to the isotropic liquid-isotropic gel phase transition by the formation of fibrous aggregates of $\mathbf{1}$ and the isotropic gel-LC gel phase transition by the exhibition of nematic phase of $\mathbf{2}$, respectively.

Variable temperature Fourier transform infrared measurements of the mixtures of 1 and $\mathbf{2}$ revealed that the driving force for gelation of $\mathbf{1}$ is mainly hydrogen bonding. Figure 4 shows the Fourier transform infrared spectra of the mixture composed of $\mathbf{1}(2.0 \mathrm{wt} \%)$ and 2 at 60,46 and $25^{\circ} \mathrm{C}$. In the isotropic state of the mixture at $60^{\circ} \mathrm{C}$
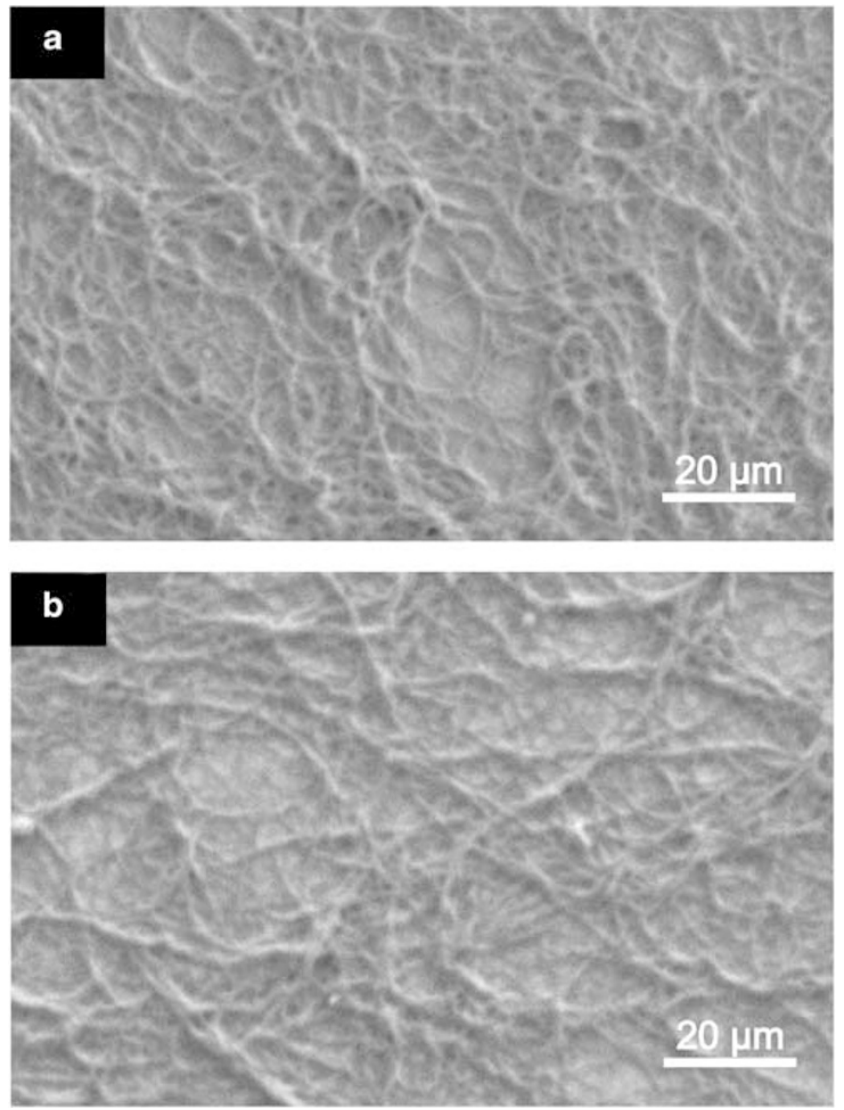

Figure 2 Scanning electron microscope (SEM) images of the fibrous networks of (a) $\mathbf{1}$ and (b) $\mathbf{3}$. The SEM samples were prepared by immersing the liquid-crystalline (LC) gels containing $1.0 \mathrm{wt} \%$ of the gelators in hexane to remove the LC molecule 2 .

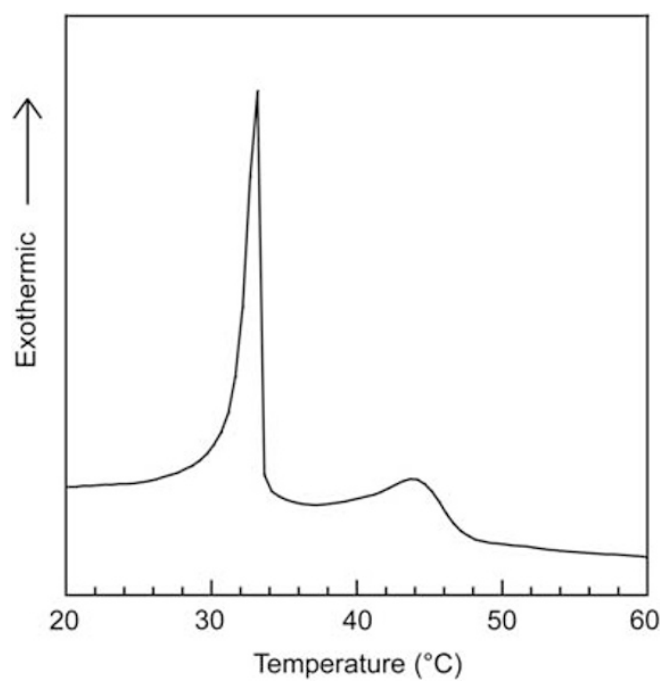

Figure 3 Differential scanning calorimetry thermogram of the mixture of $\mathbf{1}$ (2.0 wt\%) and 2 on cooling.

(Figure 4a), the $\mathrm{N}-\mathrm{H}$ stretching band of urea groups appears at $3406 \mathrm{~cm}^{-1}$, suggesting that the urea groups are free of hydrogen bonds. When the sample was cooled to $46^{\circ} \mathrm{C}$ at which LC molecule 2 is in the isotropic liquid state, a new peak was observed at $3333 \mathrm{~cm}^{-1}$ 


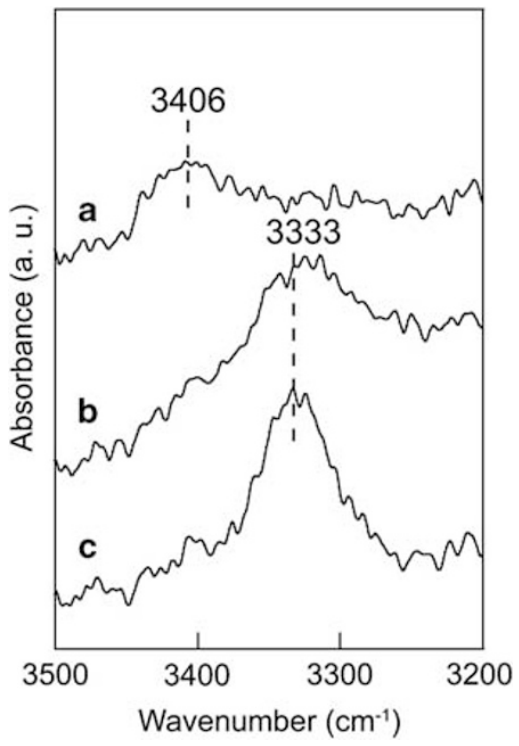

Figure 4 Variable-temperature Fourier transform infrared spectra of the mixtures of $\mathbf{1}(2.0 \mathrm{wt} \%)$ and $\mathbf{2}$ (a) in the isotropic liquid state at $60^{\circ} \mathrm{C}$, (b) in the isotropic gel state at $46^{\circ} \mathrm{C}$ and (c) in the liquid-crystalline gel state at $25^{\circ} \mathrm{C}$.

(Figure $4 \mathrm{~b}$ ). This peak is attributed to the N-H stretching band of urea groups involved in hydrogen bonding. The spectral feature of the LC gel at $25^{\circ} \mathrm{C}$ (Figure 4c) is almost same as that at $46{ }^{\circ} \mathrm{C}$.

\section{Polymerization of self-assembled fibers}

Polymerization of gelator $\mathbf{1}$ in the self-assembled fibrous state was carried out by ultraviolet light irradiation $\left(365 \mathrm{~nm}, 10 \mathrm{~m} \mathrm{Wcm}^{-2}\right.$, $30 \mathrm{~min})$ for the mixture of $\mathbf{1}(1.0 \mathrm{wt} \%), \mathbf{2}$ and radical initiator 4 $(0.1$ wt $\%)$ in the isotropic gel state at $40^{\circ} \mathrm{C}$. After ultraviolet irradiation, the infrared band of the acrylic double bond at $811 \mathrm{~cm}^{-1}$ disappeared (Figure 5). ${ }^{30}$ The polymerized sample preserved its gel state over $60{ }^{\circ} \mathrm{C}$ whereas the non-polymerized gel became the isotropic liquid state at the temperature. This gel is thermally stabilized by the networks of $\mathbf{1}$ covalently cross-linked after irradiation. The polymerized sample showed no thermal transition attributed to the dissociation of assembled 1 by differential scanning calorimetry measurement (Supplementary Figure S2). Moreover, no significant change of the morphology of fibrous aggregates of $\mathbf{1}$ before and after polymerization was observed by scanning electron microscope. measurements (Supplementary Figure S3).

\section{Electrooptical properties of nematic LC gels}

The electrooptical properties of the LC gels composed of 1 (1.0 wt\%), 2 and $4(0.1 \mathrm{wt} \%)$ before and after polymerization were examined. Figure 6 shows the photographs of the indium tin oxide cell filled with the polymerized LC gels in the electric field off- and on-states. The polymerized LC gel of $\mathbf{1}$ shows the turbid state in the absence of electric field (Figure 6a). LC molecule 2 is randomly aligned in the network of the fibers of $\mathbf{1}$ so that the LC polydomains scatter the incident light. Application of an AC electric field for the polymerized LC gel (Figure 6b) induces the light-transmitting state due to the homeotropic orientation of liquid crystal along the direction of electric field.

Figure 7 presents the relationships between transmittance and applied voltage for the polymerized LC gel $(\bullet)$ and non-polymerized LC gel $(\bigcirc)$. The electrooptical properties for the LC gels based on 1

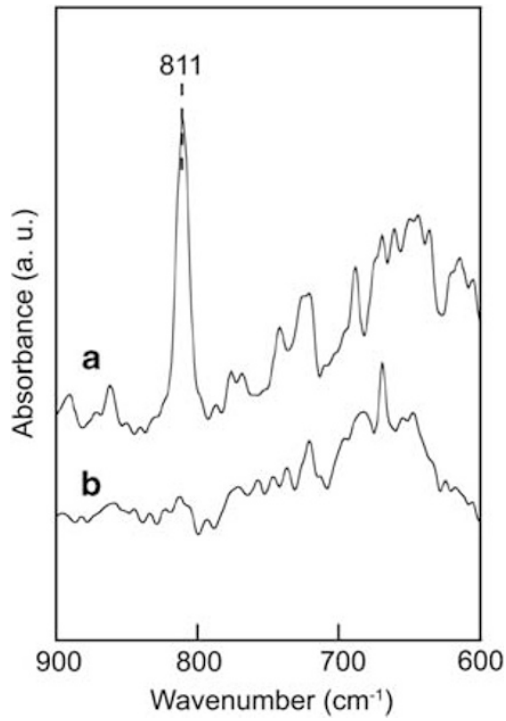

Figure 5 Fourier transform infrared spectra of the xero gels of 1 obtained from the liquid-crystalline gels containing 1 (1.0 wt\%), 2 and 4 (0.1 wt\%): (a) before and (b) after ultraviolet irradiation.
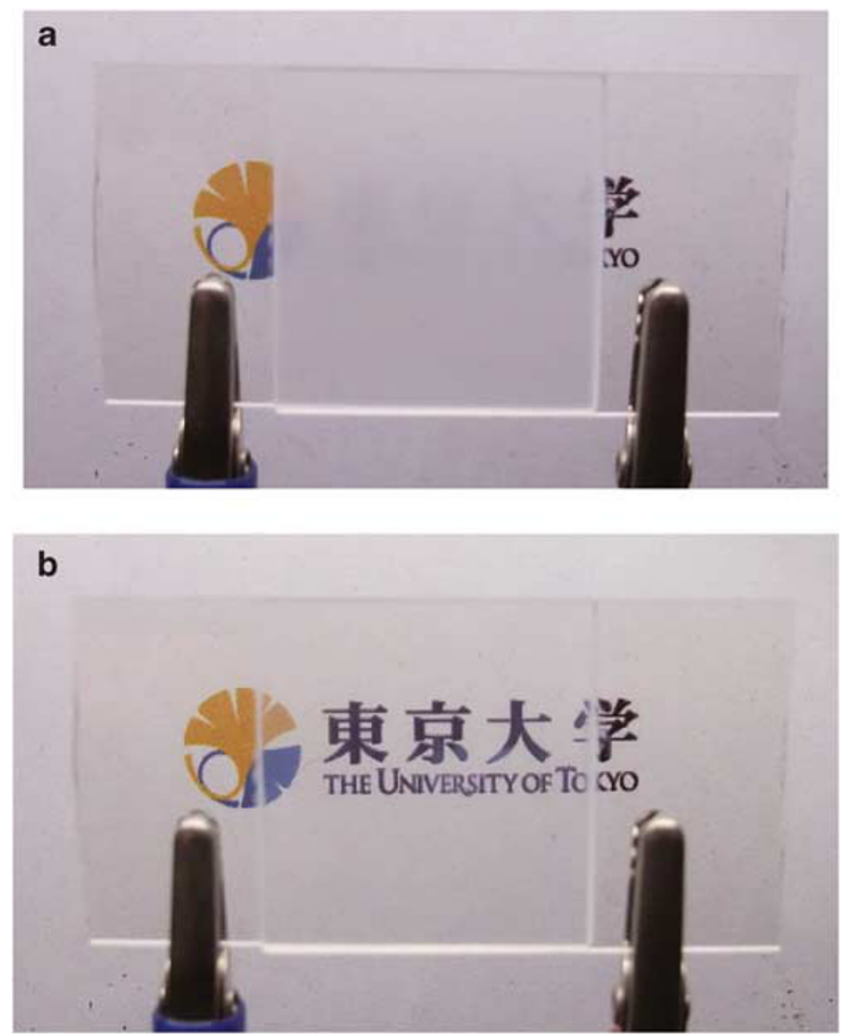

Figure 6 Photographs of the indium tin oxide (ITO) cells filled with the polymerized liquid-crystalline gel composed of $\mathbf{1}$ (1.0 wt\%), 4 (0.1 wt\%) and 2: (a) light-scattering state (OV); (b) light-transmittance state (100 V). The sample thickness is $16 \mu \mathrm{m}$. The size of ITO substrate is $3 \mathrm{~cm} \times 3 \mathrm{~cm}$

are summarized in Table 1. For the polymerized LC gel, the transmittance at $0 \mathrm{~V}\left(T_{\mathrm{off}}\right)$ is $4 \%$ and the threshold voltage $\left(V_{\mathrm{th}}\right)$ is $11 \mathrm{~V}$, whereas the non-polymerized LC gel exhibits the $T_{\text {off }}$ of $1 \%$ and $V_{\text {th }}$ of $17 \mathrm{~V}$. The saturation voltages $\left(V_{\text {sat }}\right)$ of the LC gels before and 


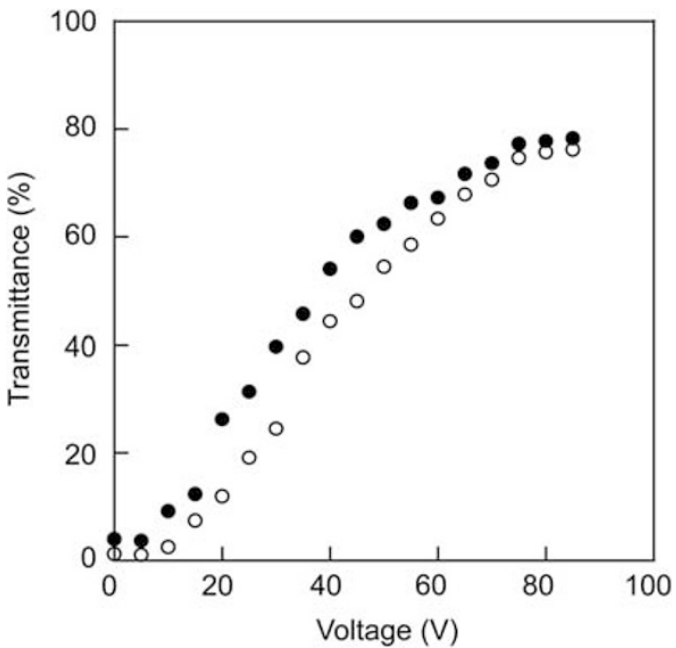

Figure 7 Transmittance of the liquid-crystalline gels composed of 1 (1.0 wt\%), 2 and $4(0.1 \mathrm{wt} \%)$ as a function of the applied voltages: for the polymerized gel (closed circle) and for the non-polymerized gel (open circle).

Table 1 Electrooptical properties of the liquid-crystalline gels of 2 with 1.0 wt\% of gelator 1 or 3

\begin{tabular}{lcccc}
\hline Sample & $\begin{array}{c}V_{\text {th }}{ }^{\mathrm{a}} \\
(\mathrm{V})\end{array}$ & $\begin{array}{c}V_{\text {sat }}{ }^{\mathrm{a}} \\
(\mathrm{V})\end{array}$ & $\begin{array}{c}\tau_{\text {on }}{ }^{\mathrm{b}} \\
(\%)\end{array}$ & $\begin{array}{c}\tau_{\text {off }}{ }^{\mathrm{b}} \\
(\%)\end{array}$ \\
\hline $\mathbf{1}$ (Before polymerization) & 17 & 67 & 76 & 1.3 \\
$\mathbf{1}$ (After polymerization) & 11 & 62 & 78 & 4.0 \\
$\mathbf{3}$ & 21 & 77 & 77 & 0.4
\end{tabular}

${ }^{\text {aThe threshold }}\left(V_{\text {th }}\right)$ and saturation $\left(V_{\text {sat }}\right)$ voltages were evaluated as voltages required to reach 10 and $90 \%$ of the maximum change in transmittance, respectively.

${ }^{\mathrm{b}}$ The transmittance in the on $\left(\tau_{\text {on }}\right)$ and off states $\left(\tau_{\text {off }}\right)$ were defined as the transmittance in the presence and absence of an electric field $(80 \mathrm{~V})$, respectively.

after polymerization are comparable. The decrease of $V_{\text {th }}$ after polymerization of $\mathbf{1}$ can be attributed to the change of the interactions between liquid crystals and fibers at their interface. The response time of the LC gels did not significantly change before and after polymerization. The polymerized LC gel showed $0.4 \mathrm{~ms}$ of the rise time $\left(\tau_{\text {on }}\right)$ and $2.3 \mathrm{~ms}$ of the decay time $\left(\tau_{\text {off }}\right)$, whereas the values of $\tau_{\text {on }}$ and $\tau_{\text {off }}$ of the non-polymerized LC gel were 0.1 and $1.6 \mathrm{~ms}$, respectively.

The electrooptical properties of the LC gels of 1 were compared with the LC gel of $\mathbf{3}$ without polymerizable groups (Table 1). The driving voltages $\left(V_{\text {th }}\right.$ and $V_{\text {sat }}$ ) of the LC gel based on 3 were higher than those of the LC gel based on 1 .

\section{CONCLUSIONS}

A new polymerizable lysine-based gelator has been developed for the preparation of liquid crystalline gels exhibiting light-scattering electrooptical properties. The randomly entangled fibrous networks of the gelator were formed in the isotropic phase of the nematic LC molecule. The self-assembled fibers were cross-linked by photopolymerization, resulting in the formation of room temperature nematic LC gel. The development of a new polymerizable lysine-based gelator in the present study enabled us to obtain electrooptical materials that exhibit stable electrooptical switching because of the formation of covalently cross-linked fibrous aggregates.

\section{ACKNOWLEDGEMENTS}

This study was partially supported by Gran-in-Aid for Scientific Research (No. 22107003) on Innovative Areas of 'Fusion Materials: Creative Development of Materials and Exploration of Their Function through Molecular Control' (Area no. 2206) (T.K.) and Scientific Research (A) (No. 23245030) (T. K.) from the Japan Society for the Promotion of Science (JSPS).

1 Demus, D., Goodby, J. W., Gray, G. W., Spiess, H.-W. \& Vill, V. Handbook of Liquid Crystals (Wiley-VCH, Weinheim, Germany (1998).

2 Kato, T., Mizoshita, N., Moriyama, M. \& Kitamura, T. Gelation of liquid crystals with self-assembled fibers. Curr. Top. Chem. (Berlin) 256, 219-236 (2005).

3 Kato, T., Hirai, Y., Nakaso, S. \& Moriyama, M. Liquid-crystalline physical gels. Chem Soc. Rev. 36, 1857-1867 (2007).

4 Kato, T., Kutsuna, T., Hanabusa, K. \& Ukon, M. Gelation of room-temperature liquid crystals by the association of a trans-1,2-bis(amino)cyclohexane derivative. Adv. Mater 10, 606-608 (1998)

5 Mizoshita, N., Hanabusa, K. \& Kato, T. Self-aggregation of a amino acid derivative as a route to liquid crystalline physical gels-faster response to electric field. Adv. Mater. 11, 392-394 (1999).

6 Mizoshita, N., Hanabusa, K. \& Kato, T. Fast and high-contrast electro-optical switching of liquid crystalline physical gels: formation of oriented microphase-separated structures. Adv. Funct. Mater 13, 313-317 (2003).

7 Mizoshita, N., Suzuki, Y., Kishimoto, K., Hanabusa, K. \& Kato, T. Electrooptica properties of liquid crystalline gels: new oligo(amino acid) gelator for light scattering display materials. J. Mater Chem. 12, 2197-2201 (2002).

8 Suzuki, Y., Mizoshita, N., Hanabusa, K. \& Kato, T. Homeotropically oriented nematic physical gels for electrooptical materials. J. Mater Chem. 13, 2870-2874 (2003).

9 Cardinaels, T., Hirai, Y., Hanabusa, K., Binnemans, K. \& Kato, T. Europium(III)-doped liquid-crystalline physical gels. J. Mater Chem. 20, 8571-8574 (2010).

10 Hirai, Y., Mizoshita, M., Moriyama, M. \& Kato, T. Self-assembled fibers photopoymerized in nematic liquid crystals: stable electrooptical switching in light-scattering mode. Langmuir 25, 8423-8427 (2009).

11 van Boxtel, M. C. W., Janssen, R. H. C., Broer, D. J., Wilderbeek, H. T. A. \& Bastiaansen, C. W. M. Polymer-filled nematics: a new class of light-scattering materials for electro-optical switches. Adv. Mater. 12, 753-757 (2000).

12 Yoshikawa, H., Maeda, K., Shiraishi, Y., Xu, J., Shiraki, H., Toshima, N. \& Kobayashi, S. Frequency modulation response of a tunable birefrigient mode nematic liquid crystal electooptic device fabricated by doping nanoparticles of $\mathrm{Pd}$ covered with liquid crystal molecules. Jpn. J. Appl. Phys., Part 241, L1315-L1317 (2000)

13 Baars, M. W. P. L., van Boxtel, M. C. W., Bastiaansen, C. W. M., Broer, D. J., Söntjens, S. H. M \& Meijer, E. W. A scattering electro-optical switch based on dendrimers dispersed in liquid crystals. Adv. Mater. 12, 715-719 (2000).

14 Crawford, G. P. \& Zumer, S. Liquid crystal in complex geometries formed by polymer and porous networks (Taylor \& Francis, London (1996).

15 Yang, D. -K., Chen, L. -C. \& Doane, J. W. Cholesteric liquid crystal/polymer dispersion for hazefree light shutters. Appl. Phys. Lett. 60, 3102-3104 (1992)

16 Kajiyama., T., Miyamoto, A., Kikuchi., H. \& Morimura, Y. Aggregation states and electro-optical properties based on light scattering of polymer/(liquid crystal) composite films. Chem. Lett. 813-816 (1989).

17 Suzuki, M. \& Hanabusa, K. L-Lysine-based low-molecular-weight gelators. Chem. Soc Rev. 38, 967-975 (2009).

18 Hanabusa, K., Nakayama, H., Kimura, M. \& Shirai, H. Easy preparation and prominent gelation of new gelator based on L-lysine. Chem. Lett. 29, 1070-1071 (2000).

19 Hardy, J. G., Hirst, A. G., Ashworth, I., Brennan, C. \& Smith, D. K. Exploring molecular recognition pathways within a family of gelators with different hydrogen bonding motifs. Tetrahedron 63, 7397-7406 (2007).

20 Edwards, W., Lagadec, C. A. \& Smith, D. K. Solvent-gelator interactions-using empirical solvent parameters to better understand the self-assembly of gel phase materials. Soft Mater 7, 110-117 (2011).

21 Shioiri, T., Ninomiya, S. \& Yamada, S. Diphenylphosphoryl azide. A new convenient reagent for a modified Curtius reaction and for peptide synthesis. J. Am. Chem. Soc. 94, 6203-6205 (1972)

22 de Loos, M., van Esch, J., Stokroos, I., Kellogg, R. M. \& Feringa, B. L. Remarkable stabilization of self-assembled organogels by polymerization. J. Am. Chem. Soc. 119 , 12675-12676 (1997).

23 Masuda, M., Hanada, T., Yase, K. \& Simizu, T. Polymerization of bolaform butadiyne 1 -glucosamide in self-assembled nanoscale-fiber morphology. Macromolecules $\mathbf{3 1}$, 9403-9405 (1998)

24 Inoue, K., Ono, Y., Kanekiyo, Y., Hanabusa, K. \& Shinkai, S. Preparation of new robust organic gels by in situ cross-link of a bis(diacetylene) gelator. Chem. lett. 429-430 (1999).

25 Tamaoki, N., Shimada, S., Okada, Y., Belaissaoui, A., Kruk, G., Yase, K. \& Matsuda, H. Polymerization of a diacetylene dicholeesteryl ester having two urethanes in organic ge states. Langmuir 16, 7545-7545 (2000)

26 Wang, G. \& Hamilton, A. D. Synthesis and Self-assembly properties of polymerizable organogelators. Chem. Eur. J. 8, 1954-1961 (2002). 
27 Kishida, T, Fujita, N., Sada, K. \& Shinkai, S. Sol-gel reaction of porphyrin-based superstructure in the organogel phase: creation of mechanically reinforced porphyrin hybrids. J. Am. Chem. Soc. 127, 7298-7299 (2005).

28 Mizoshita, N. \& Kato, T. Liquid-crystal composite of photopolymerized self-assembled fibers and aligned smectic molecules. Adv. Funct. Mater. 16, 2218-2224 (2006).
29 Moffat, J. R., Coates, I. A., Leng, F. J. \& Smith, D. K. Methathesis within selfassembled gels: Transcribing nanostructured soft materials into a more robust form. Langmuir 25, 8786-8793 (2009).

30 Decker, C. \& Moussa, K. A new method of monitoring ultra-fast photopolymerizations by real-time infra-red (RTIR) spectroscopy. Macromol. Chem. 189, 2381-2394 (1988).

Supplementary Information accompanies the paper on Polymer Journal website (http://www.nature.com/pj) 